\title{
EI bosque: cobijo del arte y metáfora de regreso desde 1968
}

\author{
Ana Esther SANTAMARÍA FERnÁNDEZ \\ Universidad Complutense de Madrid \\ Departamento de Historia del Arte III (Contemporáneo) \\ ana-sf@hotmail.com
}

\begin{abstract}
RESUMEN
El género del paisaje resurgió con fuerzas renovadas a partir de los años sesenta del siglo XX a través del land art y los earthworks. Los pioneros norteamericanos sintieron una especial predilección por el desierto y los lugares de difícil acceso para colocar sus obras, gesto que rompía las relaciones de la obra de arte con los lugares tradicionales de exposición (museos, galerías). Al tiempo, se acentuaba también la dimensión mental del arte, abriendo la vía hacia el conceptual. En los últimos años una segunda generación de creadores, que también operan en la naturaleza, elige el bosque como escenario de sus propuestas. El objeto de este trabajo es poner de manifiesto cómo en la obra de estos artistas se advierte una intención de doble retorno: por una parte, a la materialidad de la obra de arte y por otra a un origen metafórico a través de la figura del bosque, espacio que, desde la irrupción del ecologismo se entiende como sinónimo de paraíso.
\end{abstract}

Palabras clave: bosque; lugar; escultura; paseo; land art.

\section{The wood: Cover of the art and metaphor of the return from 1968}

\begin{abstract}
The landscape genre resurfaced with renewed forces beginning in the sixties of the twentieth century through the land art and the earthworks. The pioneers Americans felt a special love for the desert and the places which are difficult to access by placing their works, a gesture that broke the relations of the work of art with the traditional places of exposure (museums, galleries). At the same time, is also accentuated the mental dimension of art, opening the way toward the conceptual. In recent years a second generation of creators, which also operate in the nature, choose the forest as scenario of their proposals. The object of this work is to demonstrate how the works of these artists are warns a intention of double return: on the one hand, to the materiality of a work of art and at the other end to a metaphorical origin through the figure of the forest, a space that, since the eruption of the environmentalism is understood as a synonym for paradise.
\end{abstract}

Key words: wood; site; sculpture; walk; land art. 


\section{ALGUNAS CUESTIONES A PROPÓSITO DEL BOSQUE}

Trabajar con un concepto tan complejo como bosque requiere hacer, de entrada, unas aclaraciones respecto a su significado. El bosque es uno de esos elementos de la naturaleza que suscitan en la imaginación un sinfín de ideas controvertidas pues es, al mismo tiempo, un locus horridus y un locus amoenus. Así los bosques son, desde la antigüedad, ambientes propiciadores tanto de beneficios como de terrores para los hombres. Son una de las principales fuentes de obtención de recursos naturales y también han cumplido un significativo papel en cuanto a la canalización de la espiritualidad, pues han sido los lugares sagrados por excelencia desde tiempos remotos en numerosas culturas de nuestro planeta.

Sin embargo, a partir de la Edad Media y a consecuencia de la extensión del cristianismo, que quería terminar con todo tipo de rito pagano, predominó una visión negativa de las masas forestales. La literatura medieval ${ }^{1}$ las configuró como los lugares horribles por naturaleza, sitios a caballo entre lo maravilloso y lo terrorífico ${ }^{2}$. Así, tanto en las novelas de caballería como en las narraciones folklóricas, los héroes tienen en el bosque un escenario ineludible para desarrollar sus aventuras. Generalmente tiene relación con una serie de ritos iniciáticos que esconden su secreto entre la espesura habitada por bestias y seres maléficos. Por tanto, es también el hogar del lobo, que representa en estos relatos la faceta malvada, salvaje y hostil de la naturaleza.

Esta imagen del boque como espacio no habitable ${ }^{3}$, de tierra de nadie transitada por bestias feroces y personas que viven al margen de la ley, se prolongó hasta la Ilustración, momento en que la naturaleza se convirtió en un modelo a imitar por el hombre, y los bosques en uno de los escenarios que mejor representaban la idea de pureza. Fueron fundamentales en este punto las aportaciones de científicos como Humboldt o Linneo pero, sobre todo, el pensamiento rousseauniano, que proponía un regreso utópico al estado natural. En la vuelta al estado ideal de naturaleza que proponía Rousseau para escapar de la corrupción moral de las ciudades, el bosque se entiende como el dominio de la libertad primera y pura, de la verdad y de la felicidad. Y el salvaje como el ciudadano ejemplar de la naturaleza.

Pero no sólo la filosofía, sino también las artes plásticas han contribuido a la construcción de la imagen del bosque a través del paisaje. Este género pictórico ha colaborado a la consagración estética en el imaginario colectivo de distintos tipos de parajes naturales ${ }^{4}$. Por ejemplo, en el paisaje italiano el campo se convierte en el

1 Es interesante en este punto el siguiente artículo, aunque se centra sólo en el ámbito castellano: LÓPEZ RÍOS, Santiago, "Sobre el bosque y el lobo en la literatura castellana del siglo XV", en Nature \& Paisajes. L'émergence d'une nouvelle subjectivité à la Renaissance (Actes des journées d'étude organisées par L'École Nationale de Chartes, 26 mars et 15 avril 2005), Paris, 2006.

2 El tema es analizado en PROPP, Vladimir, Las raices históricas del cuento, Ed. Fundamentos, Madrid, 1987, pp. 76-78.

3 Esta cuestión está desarrollada en profundidad en ZUMTHOR, Paul, La medida del mundo, Ed. Cátedra, Madrid, 1994, pp. 58-61.

${ }^{4}$ La cuestión del campo en el paisaje ha sido estudiado en CAMPORESI, Piero, Le belle contrade: nascita del paessagio italiano, Ed. Gazanti, 1992, Milano; el tema del descubrimiento del mar ha sido analizado en 
espacio predilecto hasta el siglo XVIII, o el mar, que pasó de ser considerado algo horrible, que producía terror, a ser un lugar apreciado estéticamente gracias a las marinas holandesas de Van Goyen o Ruysdael, los apacibles atardeceres de Claudio de Lorena o las sublimes tempestades de Joseph Vernet. Por otro lado, las imágenes de los fotógrafos Bissón, Braun o Martens, ayudaron a dotar a la montaña de la carga estética que aún perdura en la mirada general. Del mismo modo, que cuando se piensa en el desierto americano, es muy difícil desligarse de la interpretación recibida a través del género cinematográfico del western. ${ }^{5}$

Dejando de lado numerosas manifestaciones artísticas en las que el bosque conserva ese halo de lugar misterioso y oscuro poblado de seres malignos, este estudio se centra en la construcción de la imagen del bosque como lugar amable y tangible. En este sentido, hay dos momentos en los que se ve reforzado de manera positiva y deja de ser visto como locus horridus. Estos momentos no pueden separarse de sendos fenómenos de carácter social: el higienismo del XIX y el ecologismo del XX y, en ambos casos, han sido refrendados por el arte. El primero por la Escuela de Barbizon y el segundo por algunos artistas que, después de 1968, hacen de los bosques el escenario predilecto de sus propuestas.

\section{LA RECUPERACIÓN DEL PAISAJE}

El paisaje, que había sido uno de los géneros más transitados desde el siglo XVIII, se convierte en una categoría prácticamente anatemizada desde la Primera Guerra Mundial. Podrían considerarse los últimos, aquéllos que hicieron desde las trincheras los pintores oficiales de la contienda como Felix Valloton (1855-1925) o Paul Nash (1893-1977) y que representaban parajes desolados. Sin embargo, el género reapareció con fuerzas renovadas en los últimos años de la década de los sesenta del siglo pasado a través de lo que se ha denominado land art. Las primeras experiencias, de manos de creadores como Robert Smithson (1938-1973), Walter de Maria (1935), Claes Oldemburg (1929) o Michael Heizer (1944), entre otros, consolidaron una de las aportaciones más significativas que se produjeron en el arte del pasado siglo. Esta fue la incorporación del "lugar" ${ }^{6}$ como parte compositiva de la obra de arte.

El land art surgió de manera simultánea en Norteamérica y en Europa y desde el primer momento se van a diferenciar los trabajos de los artistas norteamericanos de

CORBIN, Alain, Le territoire du vide: l'occident et le decir du rivage 1750/1840, Ed. Flammarion, 1990, Paris ; y la montaña lo ha sido en GRAND-CARTERET, John, La montagne à travers les âges, Grenoble 1903-1904, reimpresión Slatkine, 1983, Ginebra.

5 ROGER, Alain, Breve tratado del paisaje, Biblioteca Nueva, 2007, Madrid, pp.106-119.

6 En este sentido fue fundamental la repercusión que había tenido el libro de Maurice Merleau-Ponty (1908-1961). Su contribución fue esencial a la hora de dotar de sentido al contexto en el que la obra "vivía". La experiencia estética tiene una dimensión totalmente positiva al reconocer la corporalidad de la consciencia. También fue primordial la distinción que hizo Smithson entre site y non-site en SMITHSON, Robert, "A Provisional Theory of Non Sites", in Selected Writings by Robert Smithson. Essays, http://www.robertsmithson. com/essays/provisional.html, from Umpublished writings, in Robert Smithson: The collecter Writings, Ed. University of California Press, Berkeley, $2^{\text {nd }}$ ed., 1996. Site se refiere al emplazamiento en que el artista trabaja y al que la obra pertenece, y el segundo, lo hace a los espacios institucionalizados donde ésta se exhibe. 
los de los europeos. Los lugares que eligieron los primeros eran zonas inmensas e inhóspitas. Las obras más emblemáticas de estos artífices se emplazaron en desiertos: The Spiral Jetty (1970), de Smithson, en la orilla del lago salado de Utah; The lighning Field (1977), de Walter de Maria, en el desierto de Nuevo México; Sun Tunnels (1973-1976), de Nancy Holt (1938), en el desierto de Utah o Double Negative (196970), de Michael Heizer son ejemplos de este gusto por el espacio desolado.

\section{BOSQUE VERSUS DESIERTO}

El desierto es un lugar de soledad y recuerdo, donde habita la nada y en el que la presencia del hombre se entiende desde la precariedad. No sólo se concibe como una tipología de paisaje geológico, también responde a la idea de parajes urbanos deteriorados o zonas industriales abandonadas. Robert Smithson sentía una especial inclinación hacia estos espacios (fig. 1). En el fragmento siguiente perteneciente al texto que escribió para "Los monumentos de Passaic" (1967) se pone de manifiesto la sensación de exclusión de ese lugar:

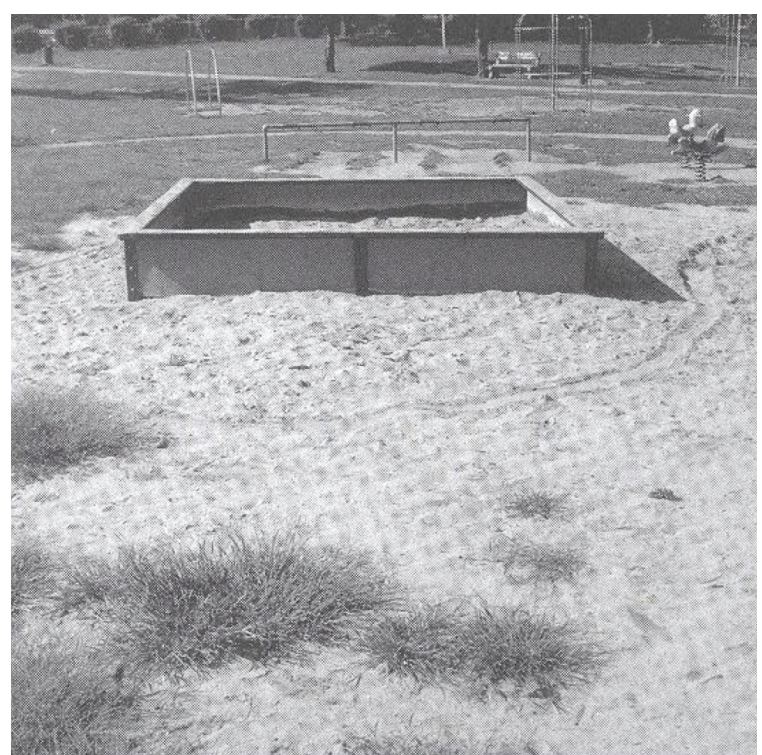

Fig. 1. Robert Smithson, The Sand-Box Monument. Monuments of Passaic (1967), (http:// www.robertsmithson.com ).

"El último monumento era una caja de arena o la maqueta de un desierto. Bajo la luz mortecina de la tarde de Passaic, el desierto se convertía en un mapa de desintegración y olvido infinitos. Este monumento de partículas diminutas resplandecía bajo un sol que brillaba tristemente, y sugería la disolución hosca de continentes enteros, la desecación de océanos. Ya no había bosques verdes y altas montañas; lo único que existía 
eran millones de granos de arena, un vasto depósito de huesos y piedras convertidas en polvo."

Del texto de Smithson se extrae una profunda sensación de no pertenencia al territorio yermo que describe. Puede entenderse este desierto visualizado en la ruina industrial como una metáfora del fracaso de la sociedad industrial, de la desconfianza en el paradigma moderno que se cuestiona el progreso y el desarrollo de la industria. La sensación que el autor describe ante la contemplación de la muerte y el abandono de Passaic entronca con la idea romántica de escisión entre el hombre y la naturaleza al tiempo que se hace patente la absoluta imposibilidad de retorno.

El historiador del arte francés Jean-Christophe Royoux piensa que la representación del desierto es inherente al arte moderno, pues representa el naufragio de la propia modernidad. El desierto fue para los artistas de land art una forma de entender la naturaleza como si se tratase de una "página en blanco" que extendía el espacio de la galería a la inmensidad del paisaje. Del mismo modo, la galería de arte moderno, el white cube, "que aísla y des-historiza cortando toda relación del arte con la vida real, también podía considerarse como una encarnación alegórica de la imagen del desierto".

Esa desolación desértica es la metáfora de una relación con el espacio que se separa del mundo 9 . En este sentido, algunos estudiosos han interpretado la colocación de estas obras en lugares desérticos, de difícil acceso y alejados de cualquier núcleo urbano, como la antesala del arte de concepto. Por ejemplo, Simón Marchán ${ }^{10}$ lo describía como la culminación del povera y del arte ecológico que daba paso al conceptual, pues se aleja de los espacios habituales de tránsito del arte (museos, galerías) yendo a lugares lejanos y dando por hecho que el espectador no se iba a trasladar al lugar propiamente dicho. Esto provocaba la separación entre el espectador y la obra de arte al tiempo que implicaba una posición intelectual activa al recibir referencias del objeto a través de fotos, videos y otros documentos como proyectos de construcción.

Aunque el desierto sea una imagen habitual en el arte reciente, otros creadores que intervienen en la naturaleza, se han decantado por los espacios verdes, cercanos a los núcleos urbanos y accesibles. En los últimos años ha proliferado en todo el mundo lugares naturales en los que se muestran las obras in situ, como los parques de esculturas o los centros dedicados al estudio de la relación entre arte y naturaleza ${ }^{11}$, la mayoría de los cuales se sitúan en zonas boscosas. Esto ha conducido en muchos casos, a la banalización y a la repetición de propuestas artísticas carentes de frescura. Este gusto exagerado por lo verde en el paisaje contemporáneo ha encontrado en el

7 SMITHSON, Robert, “A tour of The Monuments of Passaic, New Jersey”(Publisher as "The Monuments of Passaic", Artforum, December, 1967), en HOLT, Nancy, The writings of Robert Smithson, Ed. Nancy Holt, (s.1.), (s.f.), pp. 52-57.

8 ROYOUX, Jean-Christophe, "Alegorías del desierto. Reflexiones sobre un motivo recurrente en el arte actual”, en Los tiempos de un lugar (23 enero- 29 marzo 2009), CDAN, Fundación Beulas, 2009, Huesca, p. 59.

9 Ibid, p. 56

10 MARCHÁN FIZ, Simón, Del arte objetual al arte de concepto. Epílogo sobre la sensibilidad “posmoderna”, Ed. Akal, 1988, Madrid, pp. 213 y 214.

11 Algunos de ellos son el Grizedale Arts en Cumbria, Storm King, en Nueva York, Centre National D’Artet du Paisaje, en Limousin, Wanas Park, en Suecia. Y en España, los pioneros fueron la Fundación César Manrique en Lanzarote y el CDAN en Huesca. 
filósofo francés Alain Roger, uno de sus principales detractores. “¿Un paisaje tiene que ser una gran lechuga, una sopa de acederas, un caldo vegetal?" ". Y le da el nombre de "verdolatría" a esa corriente de pensamiento que confunde el valor biológico o salubre de un determinado espacio con el interés estético, simbólico o cultural, es decir, paisajístico, que tenga un paraje.

Es un hecho palmario que, desde las últimas décadas el verdor, probablemente derivado de la alta estimación que le ha otorgado el ecologismo, se viene entendiendo como sinónimo de armonía, frescura, crecimiento, fertilidad, serenidad, estabilidad, esperanza o seguridad. Este sentir ha invadido numerosos ámbitos en los que se desenvuelve la vida del hombre, desde el arte a la política. Se le ha otorgado a la naturaleza la cualidad de santidad mística, hasta el punto de que el pensamiento ecológico va ocupando lugares que las tradicionales religiones van dejando vacíos. Y lo hace con una puesta en escena muy similar a la de las confesiones más comunes. Existe un pecado: el hombre ha destruido su hábitat natural; un castigo: ha sido desterrado del entorno que fue su hogar; un paraíso: los pocos resquicios de naturaleza virgen que es preciso preservar; una redención: el ser humano puede, con un cambio de actitud, salvar la Tierra; y un más allá, pues la recompensa será el poder habitar un lugar infinitamente mejor.

El término "ecológico" aparece por doquier, incluso para referirse al arte. La obra de muchos de los creadores que se citan en este artículo es denominada, en algunos medios, arte ecológico o ecologista. Sin embargo, se entenderá arte ecológico aquel que Simón Marchán definió como el que se centra en las transformaciones energéticas entre comunidades vegetales o animales o de naturaleza inanimada y que ponen el acento en el aspecto procesual ${ }^{13}$. Se van a evitar también las expresiones eco-arte o arte ecologista, pues hablar de ecologismo, como advierte José Mará Parreño ${ }^{14}$, implica un posicionamiento activo de carácter social y político. Los creadores con los que se ha trabajado ${ }^{15}$, aunque reivindican el contacto con el medio, tienen un discurso que es más una propuesta que parte de la intimidad y la subjetividad que una propaganda política, $\mathrm{y}$, aunque estas propuestas tienen numerosos puntos de conexión, sus orígenes artísticos son heterogéneos.

Si Smithson, Heizer, Holt o De Maria acudieron a los inaccesibles desiertos americanos, Andy Goldsworthy (1956), Giuseppe Penone (1947), David Nash (1945) o Giuliano Mauri (1938- 2009), entre otros, dirigieron sus pasos hacia los bosques. Marchar al bosque, emboscarse, anima en la imaginación la idea de marchar a un lugar lejano y casi inaccesible, de penetrar en un lugar inhóspito, en tierra de nadie. Los bosques, que cobijaban los terrores más ancestrales y que siguen representando en el

12 ROGER, Alain, Breve tratado del paisaje, Madrid, Biblioteca Nueva, 2007, p. 143.

13 MARCHÁN FIZ, Simón, Del arte objetual al arte de concepto. Epílogo sobre la sensibilidad "posmoderna", Madrid, Ed. Akal, 1988, pp.213 y 214.

14 PARREÑO, José María, "Naturalmente artificial", en PARREÑO, José María (com.), Naturalmente artificial. El arte español y la naturaleza, 1968-2006, (Exposición 19 sep- 10 dic., Museo Contemporáneo Esteban Vicente, Segovia), Segovia, Museo Contemporáneo Esteban Vicente, 2006, pp. 16-18.

15 Este es actualmente un campo en constante crecimiento y, dada la proliferación de proposiciones en este sentido unida a la falta de perspectiva que se deriva de la cercanía cronológica, el análisis se ceñirá a aquéllos que han abierto la brecha y cuya coherencia artística está suficientemente consolidada. 
pensamiento colectivo la idea de naturaleza sin mancillar, son, sin embargo, uno de los espacios más antropizados y uno de los destinos preferidos del turismo ${ }^{16}$.

Encontrar hoy un trozo de tierra virginal es un imposible, pero paradójicamente, hoy más que nunca se reivindica el concepto de originario, de auténtico, de natural, como si el sentimiento de pérdida se manifestase con más fuerza que en otros momentos de la historia. "Lo primitivo como se soñaba no existe y, de existir, debió de ser hace tantos años que ahora es sólo una noción imposible" 17 , ha escrito Estrella de Diego acerca de la desaparición del exotismo en el mundo contemporáneo. Con el avance de los medios de comunicación y los transportes se han diluido las fronteras en el planeta y se han acortado las distancias. Como se apuntó, no hay punto de la Tierra que no haya sido conquistado por el hombre y que cualquiera no pueda ver desde su casa si tiene a mano un ordenador. Además, la naturaleza con la que contamos está totalmente domesticada. Definitivamente, es imposible regresar a un paraíso incólume porque el lugar de retorno ha desaparecido.

Sin embargo, la idea de regresar a un estado de naturaleza originario es un lugar común en nuestra cultura, una suerte de momento eterno y ficticio que perdura en la conciencia colectiva, una construcción cultural que, en los albores de la contemporaneidad ya definió Rousseau. En el Discurso sobre el origen de la desigualdad entre los hombres propuso una vuelta ideal al ese estado de naturaleza prístina como la única manera de escapar a la corrupción moral de las ciudades. En este contexto, entendía el bosque como el dominio de la libertad primera y pura, de la verdad y la felicidad. Pero él mismo era consciente de que ese retorno era una elaboración intelectual cuando afirmaba que:

"no es empresa liviana el deslindar lo que hay de originario y de artificial en la naturaleza actual del hombre, y conocer bien un estado que ya no existe, que tal vez nunca haya existido, que probablemente no existirá jamás, y del que no obstante es necesario tener nociones precisas para juzgar bien sobre nuestro presente."18

\section{TOCANDO EL BOSQUE}

La idea de pérdida de lo exótico y la imposibilidad de regresar a un origen, podría ser canalizado a través de un doloroso sentimiento de nostalgia y, sin embargo, es una cuestión asumida por todos estos artistas del bosque sin dramatismo. Los espacios forestales que eligen son espacios cercanos a las ciudades, a los que el público tiene un fácil acceso y que han sido profundamente intervenidos por el hombre. En ocasiones son áreas vecinas a sus lugares de residencia, sitios que les resultan familiares. Es el caso de Giuseppe Penone, uno de los pioneros que instaló sus piezas en la foresta. Él

\footnotetext{
16 AUGÉ, Marc, El viaje imposible. El turismo y sus imágenes, Ed. Gedisa, Barcelona, 1998, pp. 45-60.

17 DIEGO OTERO, Estrella de, Quedarse sin lo exótico, Fundación César Manrique, Lanzarote, 1999, p. 38 .

18 ROUSSEAU, Jean-Jacques, Discursos sobre las ciencias y las artes. Discurso sobre el origen de la desigualdad entre los hombres, Valencia, Universidad de Valencia, 1990, p. 62.
} 
realizó su primera escultura en el bosque de su pueblo, Garesio y no mostraba, en absoluto, ningún interés por buscar un lugar recóndito. Dijo Penone de este lugar en una entrevista: "Escogí un terreno a orillas de un río porque era de fácil acceso y no estaba totalmente perdido en el bosque". En esta obra plasma el deseo de reencontrarse con la naturaleza y de fundirse con ella.

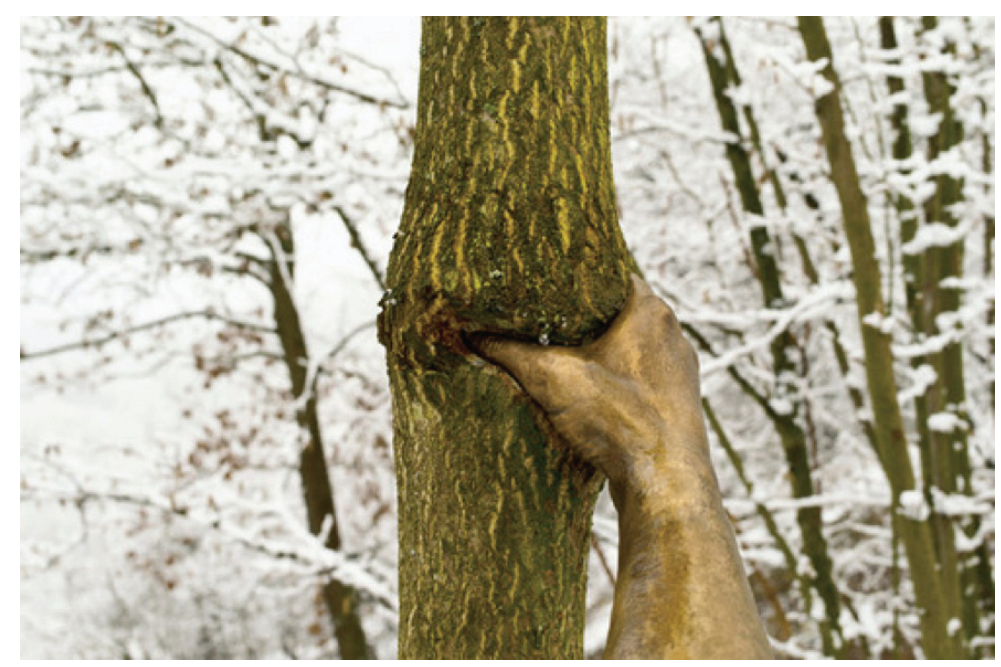

Fig. 2. Giuseppe Penone, Continuerá a crescere tranne que in quel punto. Alpi Maritimi, Bosque de Garesio, Italia, 1968.

(http://tobia.tumblr.com/post/1388962596/giuseppe-penone ).

Esta primera obra de 1968 fue Alpi maritimi, que consistía en una serie de esculturas elaboradas alrededor de la idea de los árboles. En una de ellas, Continuerá a crescere tranne que in quel punto (Continuará creciendo excepto en aquel punto), pone de manifiesto esta voluntar de volver a encontrarse con la naturaleza y de fundirse con ella (fig. 2). Eligió una zona boscosa cercana a su casa, en el norte de Italia y realizó la intervención en un árbol nuevo. Modeló una réplica de su mano agarrando el tronco, que después fue fundida en bronce y colocada en el propio árbol. La idea era que si una persona agarrase con su mano el fino tronco de un árbol joven y no se moviese durante varios años, modificaría el desarrollo de la planta. El árbol, con el paso del tiempo ha crecido alrededor de la mano, produciendo sobre ésta otro abrazo que envuelve al primero. La voluntad del escultor era poner en evidencia la diferencia del tiempo y el ritmo vital del hombre y del árbol y ajustar sus parámetros para que pudiesen fluir juntos:

"Siento la respiración de la floresta, oigo el crecimiento lento e implacable de la madera, modelo mi respiración sobre la respiración del vegetal, percibo el deslizamiento del árbol alrededor de mi mano apoyada en su tronco. El cambio de relación temporal vuelve fluido lo sólido y sólido lo fluido. La mano se hunde en el tronco del árbol que 
por la velocidad del crecimiento y la plasticidad de la materia es el elemento fluido ideal para ser plasmado" 19 .

Esta necesidad de fusión con el entorno subyace también en las producciones de Andy Goldsworthy. "Necesito la tierra, la necesito,...", repite como en una letanía el artista al comienzo de la película Rivers and tides, dedicada a la obra del artista británico. Andy Goldsworthy, -que trabajó mucho tiempo como peón en varias granjas-, en la primavera de 1976, comenzó a elaborar varias esculturas en un bosque cercano a Grove Farm, el lugar en el que trabajaba. Era una zona que le resultaba familiar y le ayudaba a ubicarse sin problemas. Ha sido una constante en su obra el "crear lugares conocidos" 20 . Su trabajo, sobre todo al principio de los 80 , se emplaza en estas áreas forestales colindantes con granjas, fincas o pequeños pueblos. Aunque conserven el recuerdo del lugar salvaje que un día fueron, son espacios profundamente domesticados.

Goldsworthy se encuentra cómodo en estos parajes elaborados que no han dejado de ser "naturales". En la instalación que elaboró en 2007 para el Palacio de Cristal del Retiro de Madrid titulada En las entrañas del árbol, trabaja con árboles de un bosque relativamente joven, el de la cercana Sierra de Guadarrama. No quedan ya restos del bosque originario, es una zona bastante urbanizada y los árboles son fruto de las repoblaciones realizadas en el siglo XIX y las de después de la Guerra Civil. Los árboles con los que construye las cabañas de la instalación, -que serán después devueltas a su lugar de origen-, están destinados a ir al aserradero para ser cortados y después destinados a la construcción. El artista quiere que las personas que vean esta obra sepan de dónde proceden muchas de las cosas que usan a diario. Que aunque vivan en la ciudad, que comprendan que ésta es también naturaleza y que conozcan la labor de otras gentes que trabajan en el bosque, que no es ya un bosque natural, sino sembrado, a su vez, por otras personas. De este modo, crea una conexión entre la urbe y su origen que es, topográficamente hablando, bastante próximo.

David Nash (1945) es otro de los artistas que prefiere trabajar en lugares cercanos a su casa. Ha establecido una ligazón que va más allá del terreno profesional con Cae'n-y-Coed, una zona próxima a su residencia en el norte de Gales. Estas tierras las heredó de su padre. En 1977, en un claro del bosque plantó veintidós fresnos formando un círculo de veinte metros de diámetro. Ha ido podando e injertando los troncos y modificando la trayectoria de su crecimiento para que, con el tiempo, lleguen a formar una cúpula vegetal. Ash Dome es una obra viva, que abandona la imagen de una naturaleza prístina e intocable. La esencia de la escultura es la transformación de la naturaleza a través de la intervención humana. Y esta transformación está llevada a cabo en un terreno doméstico que conecta, para el autor, las raíces familiares con aquéllas que quiere establecer con el corazón del bosque que le sirve de cobijo.

19 FERNÁNDEZ CID, Miguel, Giuseppe Penone 1968-1998 (Exposición 22 enero-4 abril 1999), (s.1.) Xunta de Galicia, Conselleria de Cultura, Comuniciación Social e Turismo, 1999, pp. 47-48.

20 FISKE, Tina, "Andy Goldsworthy: 'Fui al bosque'”, en PARREÑO, José Ma; Museo Nacional Centro de Arte Reina Sofía, 2007, Madrid, p. 27. 


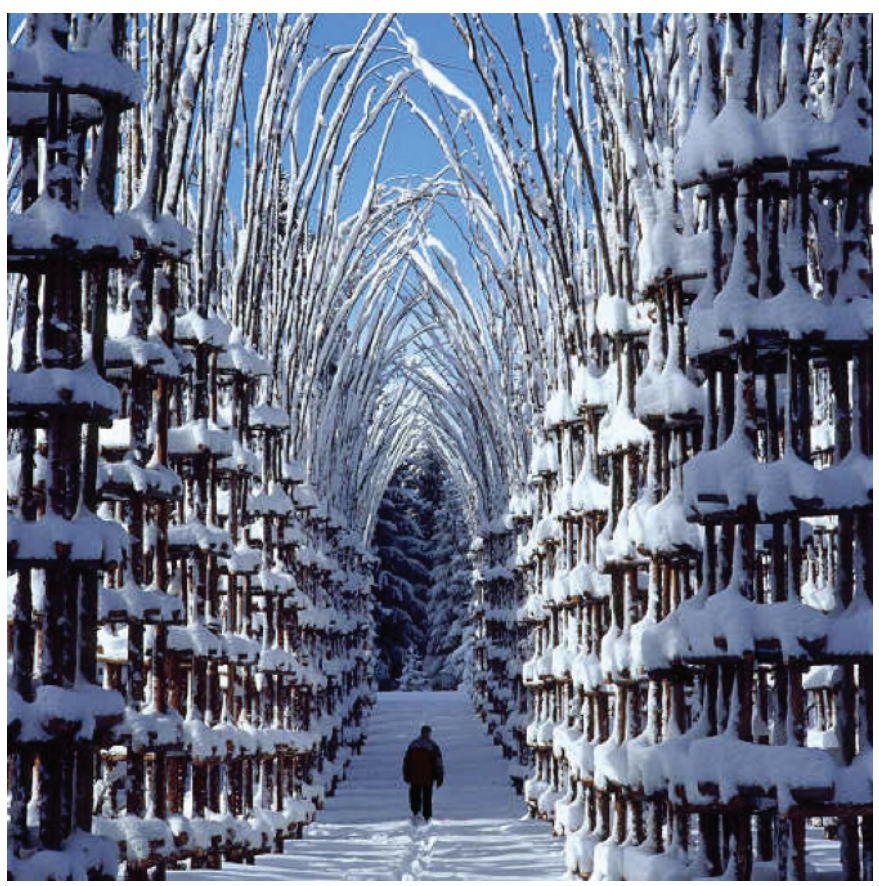

Fig. 3. Giuliano Mauri, Cattedrale Vegetale, Artel Sella, Malga Costa, Italia, 2001.

(GÓMEZ AGUILERA, Fernando (com.); Giuliano Mauri (exposición 16 jun.- 18 sep. 2005, Lanzarote, FCM), Lanzarote, Fundación César Manrique, 2005, p. 115).

(http://www.fcmanrique.org/recursos/publicacion/Obras\%20IV.\%20Proyectos\%20realizados.pdf).

Algunas de las obras más representativas de Giuliano Mauri (1938-2009) surgen alrededor de la idea de naturaleza como refugio: Casa dell 'uomo raccoglitore (1981), Trane di memoria (1993) o Cattedrale vegetale (2001). Esta última está situada en un claro de los bosques de Malga Costa, en los Alpes Dolomitas (fig. 3). Recuerda una catedral gótica, con pilares construidos con armazones de madera dentro de los cuales se han puesto plantas que, al ir creciendo ascensionalmente, terminarán por unirse formando un templo en el que el hombre recuerde su alianza con el mundo a través de la naturaleza. Acerca de esta pieza decía el autor:

"Dentro de estas estructuras artificiales que estoy construyendo habrá carpes. Construyo estos artificios para acompañar a la planta durante los veinte años que necesita para ser adulta. Después de este tiempo las estructuras se pudrirán y se volverán tierra. En su lugar, habrá ochenta plantas con forma de columna que recordarán mi trabajo. Cuatro hileras de árboles para la catedral que siempre he soñado. Dentro de veinte años, la gente se dará cuenta que ha sido la creación de la naturaleza la que ha dialo- 
gado con el hombre. Que es lo que el hombre siempre había hecho. El olvido es sólo nuestro de no saber, de no reconocer." ${ }^{21}$

Cuando desaparezca la huella del trabajo del hombre quedará el recuerdo vivo a través del cual se establecerá la alianza con el entorno, una alianza que está impregnada de misticismo y que se pone en conexión con la cualidad sagrada de los bosques. Porque hubo un tiempo ancestral en el que la naturaleza tenía una connotación sacra que hoy parece que se ha olvidado. Los hombres de este tiempo podían comunicarse con la divinidad que se manifestaba a través de elementos naturales como piedras, fuentes o árboles. Mircea Elíade acuñó el término "hierofanía" para describir la manifestación de lo sagrado a través de objetos y materiales del mundo tangible. A lo sagrado se accede a través de la materia. Elíade también comparaba al artista con el hombre de épocas prehistóricas en cuanto a que ambos pueden tomar consciencia de la existencia de lo sacro a través de los materiales. ${ }^{22}$

\section{LA "HIEROFANÍA" DE LA MATERIA}

El material, tomado de la naturaleza y apenas trabajado, muestra la realidad de su sustancia. La forma no coarta la expresividad de la materia, que vuelve a adquirir un sentido profundo y conecta las obras con sus lugares de origen. El artista puede así, establecer una comunicación con el espectador:

"Espiritualizamos los materiales mediante nuestro trabajo con ellos. Inconscientemente estamos creando un lenguaje que otro ser humano puede captar. Nos conectamos con esa cualidad espiritual que se ha puesto en el material. Esto no se hace por ritual, se hace simplemente por sentido común". ${ }^{23}$

Apelar al sentido común y compartido viene a reivindicar aspectos que se encuentran en la esencia del ser humano y le coloca de nuevo ante el mundo del que se escindió. Es una llamada al hombre a ponerse de nuevo en contacto con el medio y volver a comprender su lenguaje.

"El uso
De materiales orgánicos
Abono
Madera
Y tierra
Tierra roja
De colinas metalíferas
Llena de recuerdos.

Estos

21 Arte Sella, La cattedrale vegetale. Giuliano Mauri, http://www.artesella.it/persorso/31.html

22 ELIADE, Mircea, El vuelo mágico, Ed. Siruela, 1977, Madrid, pp. 141-144.

23 GRANDE, Jonh K., Diálogos Arte-Naturaleza, Fundación César Manrique, 2005, Lanzarote, p. 39. 


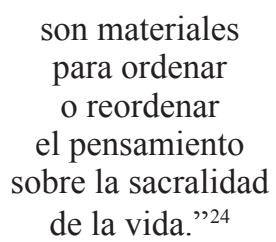

Giuliano Mauri fue en sus comienzos un artista conceptual. A mediados de los años ochenta del siglo pasado, sus preocupaciones se focalizaron en el paisaje y la naturaleza. Mauri sentía predilección por materiales que tomaba directamente del lugar en el que trabajaba. Utilizaba sobre todo palos y ramas con los que construía estructuras que después se fundían con el entorno sin imposición violenta. Su trabajo estaba enlazado con prácticas artesanales remotas y apenas utilizaba otra herramienta que la mano. En las obras de Mauri se advierte el movimiento de trenzar, de atar, de anudar, actos creadores alejados de todo refinamiento tecnológico. En sus esculturas se detecta el automatismo manual, como si se tratase de una herencia recóndita que pervive en el inconsciente de los hombres, apartado de todo rastro de intelectualidad $\mathrm{y}$, sin embargo, lleno de memoria.

La actividad práctica en el arte ha sido un tema de debate desde Duchamp y el empeño en eliminar todo rastro de la mano del artista, enfatizando en la carga intelectual es la corriente predominante en el arte actual. Sin embargo, a través del análisis de la obra de los artistas que, desde aquí se está haciendo referencia, se plantea también la reivindicación de la presencia de la mano en el arte. En la década de los noventa se publicó el libro de Frank R. Wilson: La mano. De cómo su uso configura el cerebro, el lenguaje y la cultura humana ${ }^{25}$. El neurocirujano ponía de manifiesto el papel que ha jugado la mano en el desarrollo del hombre como especie. A lo largo del libro se hace eco de las investigaciones que se han dirigido sobre este tema desde otras disciplinas. Por ejemplo, el lenguaje, cuyo origen estaría en el gesto que precede a la palabra. Plantea la imposibilidad de separar lo que está en la mente y lo que reside en el cuerpo. Incluso la palabra concepto, que se refiere a la idea o entendimiento y se sitúa plenamente en el campo intelectual, delata un origen corporal. Concepto procede del latín concipire (concebir) que, a su vez lo hace de capere (agarrar o capturar algo) y el término agarrar es indiscutiblemente corpóreo.

Cuando la mano se enreda entre las ramas, cuando cose, une, ata o trenza, es también una proyección del cuerpo que se pone en contacto con la materia. Los elementos sencillos que utiliza Mauri traen a la memoria recuerdos de un tiempo originario y se relacionan con actividades elementales de la evolución humana. El aspecto que tenía su taller de Lodi podría pasar por el de un cestero.

La cestería fascinó también a Chris Drury (1948) cuando leyó que los nativos del suroeste de los EEUU cuando tejían no sólo creaban un objeto sino que ponían en él

24 “L'uso/di materiali organici/letal/legno/e terra/terra rossa/di colline metalifere/ pregna di memorie./ Questi/ sono materiali/ per ordinare/ o riordinare/ il pensiero/ sulla sacralitá/ della vita", en VVAA, Lignea, Ed. Mazzotta, Milano, 2000, p. 44.

25 WILSON, Frank R., La mano: De cómo su uso configura el cerebro, el lenguaje y la cultura humana, Ed. Tusquets, 2002, Barcelona. 
el espíritu de toda la tribu. Le interesó esa parte que no se ve pero que está en el oficio y que nuestra cultura occidental parece haber perdido y que tiene algo de repetitivo e hipnótico. "Repetir una acción se parece a cantar un mantra o estar en un estado perpetuo de meditación" ${ }^{26}$. Como una letanía que se pronuncia una y otra vez, Giuliano Mauri, Chris Drury o Andy Goldsworthy utilizan la reiteración en sus esculturas trabajadas con las manos. Insisten en las mismas estructuras: cabañas, refugios, nidos, agujeros o espirales. Redundar, repetir, decía Kierkegaard "lleva a conseguir una gran interioridad" 27 . Es un gesto que conduce a profundizar en el sentido de las cosas y en el aprendizaje íntimo de las mismas. Si algo se repite, quiere decir que ya ha existido y que, de algún modo, se recuerda. La reiteración ayuda a conocer mejor el mundo.

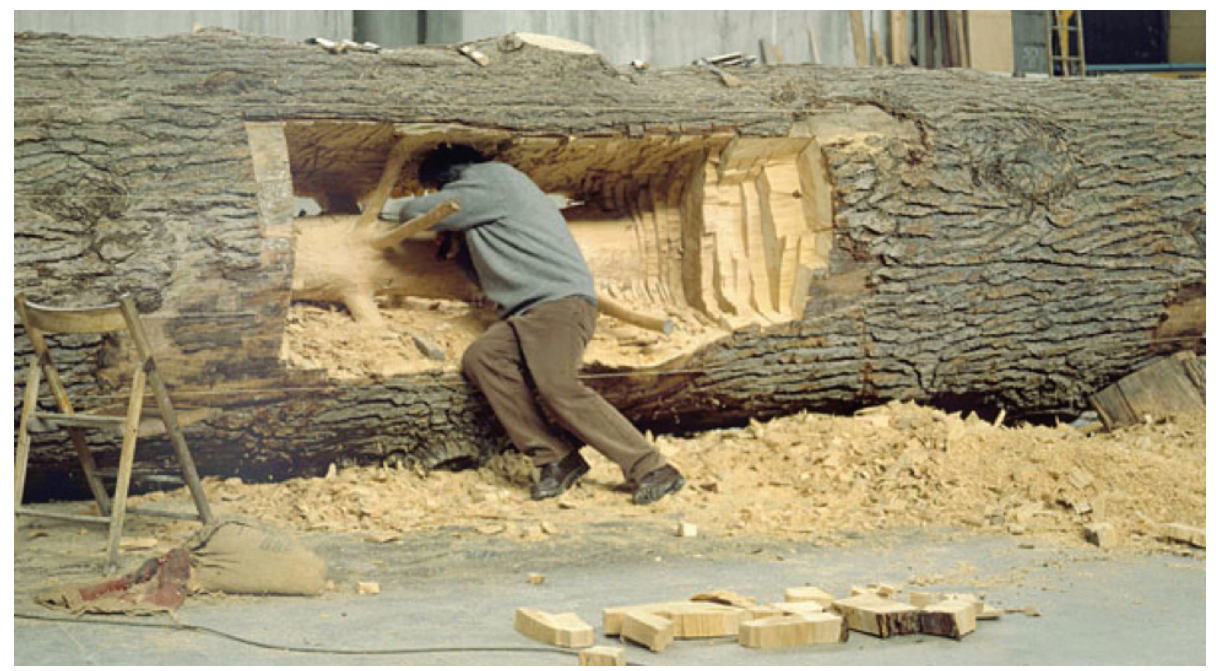

Fig. 4. Giuseppe Penone trabajando con un gran tronco de árbol en su taller. (http://emilyiremonger.wordpress.com).

El conocimiento del mundo para estos creadores pasa por la mano a través de los materiales que, a su vez, proceden del bosque. Giuseppe Penone, en Ripetere il bosco (fig. 4), una idea sobre la que ha vuelto muchas veces desde 1968, coge trozos de madera intervenidos por la civilización y va excavando, como si se tratase de un ejercicio arqueológico, y sacando a la luz la figura del árbol que esa pieza fue hace muchos años. A golpe de gubia ha ido retrocediendo anillo por anillo, como en un flashback, como si el árbol hablase al artista para que le devuelva su forma primera. Mientras realiza estas esculturas, Penone desbasta la madera metido por completo dentro del tronco, estableciendo una relación casi carnal con el material.

Alberto Carneiro (1937) en Meu corpo vegetal, también encuentra a través del árbol el camino que le devuelve al seno de la naturaleza. No en vano madera y materia

26 GRANDE, Jonh K., Op. cit. , p. 412.

27 KIERKEGAARD, Sören, La repetición, Alinaza Editorial, 2009, Madrid, p. 58. 


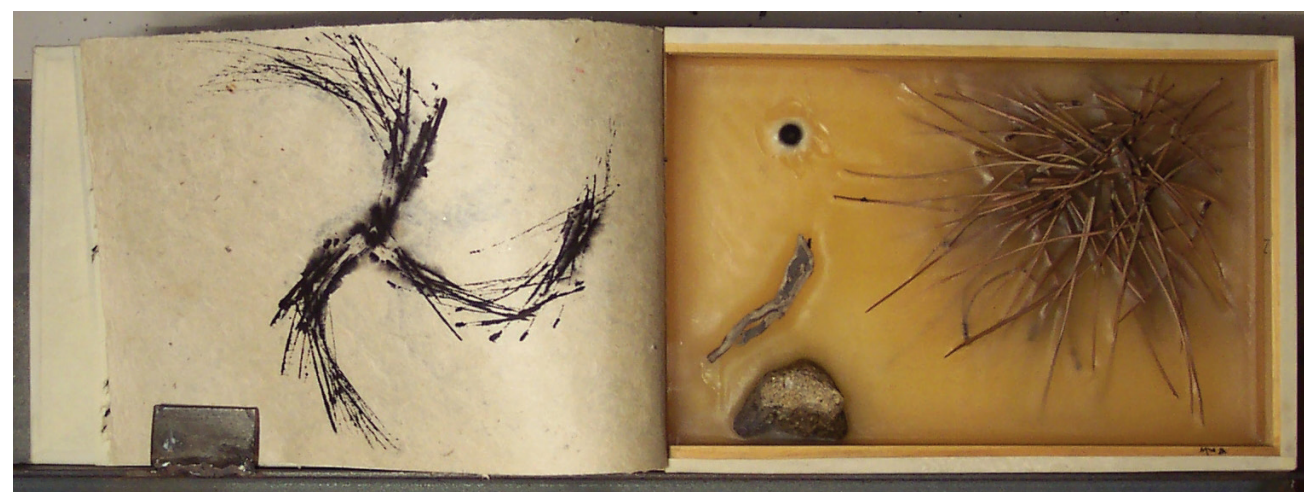

Fig. 5. Miguel Ángel Blanco, Libro $n^{\circ}$ 502, Acículas celtas. Flor de nieve negra. 1.11.1992. (http://bibliotecadelbosque.net )

(Imagen cedida por el artista).

comparten un origen etimológico común con madre, mater. El bosque es, desde el punto de vista simbólico, una manifestación del principio femenino ${ }^{28}$. Este regreso al origen lo vive el artista portugués a través de la búsqueda de la fuerza esencial que surge de la materia y que no ha de ser camuflada por la imagen. "Muchas imágenes inventadas no pueden vivir porque son simples juegos formales, porque no están verdaderamente adaptadas a la materia que deben adornar" ${ }^{29}$. Afirmaba el filósofo francés Gaston Bachelard que no sólo la forma, sino la materia posee también la facultad de traer a la memoria imágenes que además son figuraciones familiares para la mano, pues la materia conserva la memoria de lo táctil.

Miguel Ángel Blanco mientras camina está atento a estas manifestaciones sagradas que le revela el bosque (fig. 5). Los humildes objetos que recoge son ordenados en los libros-caja, también compuestos por materiales de origen forestal. Estas piezas encierran el olor de las hojas del bosque, el lenguaje de los pájaros o los sonidos de las tormentas que nos hablan de la antiguan ligazón entre los hombres y los árboles. Las cajas son de madera y cristal, y evocan dos de los principales elementos "hierofánicos" de la naturaleza: el árbol y la piedra. La parafina, las resinas, las ceras o el papel sobre el que imprime la secuencia narrativa proceden del bosque. El libro, elemento primordial de la cultura, tiene su origen etimológico en liber, que es la parte más profunda de la corteza arbórea.

El bosque no será sólo el origen y el refugio del hombre, sino también de la civilización. Así lo ha entendido este artista madrileño que toca el libro y toca el árbol. Así lo entendieron también los celtas o los indios, que aprendían las enseñanzas de sus maestros en el corazón del bosque. O como se muestra al final de la película Fahrenheit 451, de François Truffaut, basada en la novela homónima de Ray Bradbury.

28 CIRLOT, Juan Eduardo, Diccionario de símbolos, Círculo de Lectores, 1997, Madrid, p. 112.

29 BACHELARD, Gastón, El agua y los sueños, Fondo de Cultura Económica, 1994, México, p.10. 
En ella, la foresta se convierte en el refugio de los hombres que se han convertido en libros vivientes para preservar la cultura.

Estos bosques domesticados a los que se acercan estos artistas, han perdido cualquier connotación negativa debido, sobre todo desde las últimas décadas, a la irrupción del pensamiento ecológico que ha elevado el valor de los espacios verdes hasta la casi sacralidad. Pero no se trata de un lugar idílico al que no se puede volver, sino un lugar accesible y cercano. Casi siempre trabajan en bosques secundarios, profundamente antropizados desde tiempos inmemoriales. Sin embargo, esto no quiere decir que los bosques no conserven su faceta ensoñadora, pues es algo que subyace en le pensamiento de la colectividad. Convertido en algo cotidiano mantiene, no obstante, su faceta de salvaje y maravilloso.

La cercanía que se quiere transmitir se percibe también por la fuerte presencia que tiene el material en las obras que estos artistas hacen. Se rememora un lenguaje plástico originario que se pone en relación con antiguos oficios en algunos casos y, en otros, por el abandono total de la herramienta en pro del hacer de la mano desnuda, llevando a un segundo plano el componente mental del arte.

Estos creadores plantean un retorno al origen representado por la figura del bosque. Un bosque que se ha convertido en una posibilidad tangible de vuelta al paraíso. Edén domesticado que sirve de cobijo al hombre y al arte, donde la obra de aquel se funde con el entorno. Un lugar en el que cultura y naturaleza encuentran el equilibrio y que propicia el reestablecimiento de aquella alianza olvidada. 